\title{
Fluoride Releasing/Recharging Ability of Bulk- Fill and Resin Modified Glass Ionomer Cements After the Application of Different Surface Coating Agents: An In -Vitro Study
}

\author{
Shaymaa I. Habib ${ }^{1}$ \\ ${ }^{1}$ Biomaterials Department, Faculty of dentistry, Cairo University \\ Email: shaymaa.habib@dentistry.cu.edu.eg \\ Submitted: $23-3-2020$ \\ Accepted: 31-5-2020
}

\begin{abstract}
Objective: Evaluate the effect of nano-filled coating on fluoride release/recharging ability of Equia forte Fil and Fuji II LC glass ionomer cements in comparison to commonly used surface coatings; universal adhesive and petroleum jelly.

Methodology: 24 disc-shaped samples for each group were prepared with glass hybrid (Group I) and resinmodified glass ionomer cement (Group II). Each group was divided into four subgroups; 1: Control, 2: Equia Forte Coat, 3: Single bond Universal and 4: Petroleum jelly. Fluoride ions released was measured at different time intervals using fluoride-specific ion-electrode. After 63 days, samples were immersed in sodium-fluoride gel and fluoride recharge capability was evaluated.

Results: Application of coats on glass hybrid resulted in significant decrease in fluoride ions release at all tested time intervals, in comparison to control group ( $\mathrm{p}<0.0001)$. The least ions release was recorded in nano-filled coat and universal adhesive. For RMGIC, delay in burst release was observed after coating, with the least fluoride release recorded in nano-filled coated subgroup. All groups showed the ability to recharge with $\mathrm{NaF}$ gel and re-release again.

Conclusions: 1. Application of coatings has dramatic reducing effect on fluoride ions release/recharging ability. 2. Nano-filled coating and universal adhesive have a hindering influence on fluoride ions release more than petroleum jelly.3. The effect of nano-filled coating is more evident on glass hybrid than on resin- modified glass ionomer cement. 4. Application of coatings on glass hybrid and RMGIC delayed the burst release but maintained the fluoride release ability of GICs at constant level.
\end{abstract}

Keywords: Fluoride Release, Glass Hybrid Cements, Nano filled Coat, Petroleum Jelly, Universal Adhesive

\section{Introduction:}

Dental caries is considered as one of the most prevalent chronic disease that affects the majority of children as well as the adults (1). Insufficient fluoride exposure is a causative factor besides dietary habits, cariogenic bacteria, low salivary flow and poor oral hygiene. The anticariogenic property of fluoride is mainly related to the inhibition of bacterial metabolism and growth, prevention of demineralization and acceleration of the remineralization procedures (2). For that reason, the fluoride release and recharging capability is considered as an important property of dental restorative materials. 
It is well-known that fluoride releasing materials used for prevention of dental caries are glass ionomer cements (GIC). Beside the longterm fluoride release, glass ionomer is a biocompatible material and can bond chemically to the tooth substrate $(3,4)$. However, conventional GIC have certain disadvantages, like, extended setting reaction, low mechanical properties, poor esthetics and moisture sensitivity (3). Consequently, many attempts were conducted to ameliorate the physical and mechanical properties of these cements. Resinmodified glass ionomer cement (RMGIC) has been introduced at the end of 1980, where watersoluble polymer was added that rendered the material stronger, less brittle and light cured (5). In 2007, a new GIC technology was presented based on the development of highly viscous glass ionomer cements via optimization of the polyacid and better particle size distribution (Equia, GC, Tokyo, Japan). This resulted in high cross linkage in the glass ionomer matrix that greatly improved the physical properties of the cement (6,7). Later in 2011, the manufacturer renamed this cement to what so called "Equia Fil"(7).

More recently, EQUIA Forte Fil (GC, Tokyo; Japan) was introduced into market as class $\mathrm{V}$ and posterior restorations. It is glass hybrids ( $\mathrm{GHs}$ ) self-cured GIC that combine the highly viscous conventional GIC (EQUIA Fil) with a new self adhesive nanofilled resin coating agent (EQUIA Forte Coat) $(8,9)$. The reinforcement of glass ionomer materials included the introduction of higher molecular weight acid molecules with highly reactive smaller silicate fillers that in turn increased the matrix crosslinkage (8). The nanofilled resinous coating supplied with the cement allows protection till maturation is completed during the first months and its glaze effect ameliorates the optical property of the cement $(10,11)$. It was found that this coat improves the wear resistance, fracture strength and marginal integrity of the cement through proper infiltration of the GIC surfaces $(12,13)$.

Actually, there is a lot of debates concerning the influence of coatings agents on the fluoride release efficacy as well as the recharging ability of these GICs restorations. Therefore, the aim of the present study was to evaluate the effect of nano-filled coating on the fluoride release/recharge ability of Equia forte Fil and Fuji II LC glass ionomer cements in comparison to the commonly used surface coatings; universal adhesive and petroleum jelly.

The null hypothesis of the current study was; there would not be a statistically significant differences between the fluoride release/recharge ability of the two investigated glass ionomers restorative materials; glass hybrid self-cured GIC and light cured RMGIC, after the applications of different surface coating agents at the different time intervals.

\section{Materials and Methods}

Materials used in the present study are presented in Table 1.

\section{Sample Size Calculation:}

Sample sizes for fluoride release test and fluoride recharge test were conducted according to Brzovic Rajić et al (7) and Rao et al (14) respectively. The calculation was performed with G*Power (version 3.1.9.2 for sample size analysis) at $\alpha=0.05$, effect size $=1.28$. Six samples/subgroup were prepared to gain a power of $99 \%$.

\section{Samples Preparation:}

Twenty-four disc shaped samples for each test group were prepared, according to manufacturer's instructions, with glass hybrid and resin-modified glass ionomer cements. The capsules of glass hybrid self-cured GIC (Group I: Equia Forte Fil, E) and light cured RMGIC (group II: Fuji II LC, F) were shook before mixing for activation, placed into amalgamator (Softly, Acteon group, Italy) and mixed for $10 \mathrm{sec}$ at high speed. The pastes were then extruded into cylindrical split Teflon molds $(8 \mathrm{~mm}$ diameter, $2 \mathrm{~mm}$ thickness) supported by a glass plate and covered with polyester strip. The surface area of each sample was $150.72 \mathrm{~mm} 2$, that nearly corresponds to class $\mathrm{V}$ restorations. The mold was filled with the different materials and covered with another polyester strip and a glass plate, and clamped to obtain a flat smooth surface (15). According to manufacturer's 
instructions, the setting time of glass hybrid GIC was $2.5 \mathrm{~min}$, while the RMGIC was light-cured for 20sec at each surface using Bluephase C5 LED curing light (Ivoclar, Vivadent).

\section{Samples Grouping:}

Samples for each test group were randomly assigned into 4 subgroups (6 samples/subgroup) (www.researchrandomizer.org) according to the surface coatings used as follow:

Subgroup 1: Control (No coat) (E/F)

Subgroup 2: Equia Forte Coat LC (EF, FF)

Subgroup 3: Single bond Universal (EU/FU)

Subgroup 4: Petroleum jelly (Vaseline) (EV/FV)

The light-cured coats were applied on all the exposed surfaces, including the lateral ones with a microbrush, and light-cured for $20 \mathrm{sec}$ using LED curing light as stated by the manufacturers. Petroleum jelly was applied using a brush, then air dried.

\section{Fluoride Release and Recharge Analysis:}

The samples were kept at $37^{\circ} \mathrm{C}, 100 \%$ relative humidity in an incubator (CBM, Torre Picenardi, Italy) for $24 \mathrm{hrs}$. Then, the samples were suspended individually in well-sealed polyethylene vials containing $10 \mathrm{ml}$ deionized water $\left(\mathrm{pH}\right.$ 6.5) and incubated at $37^{\circ} \mathrm{C}$. The released fluoride ions were detected at $1,7,14$, 21, 28, 35, 42, 49, 56 and 63 days. At each time interval, the samples were gently removed from the vials, washed with deionized water and dried using absorbent paper for $2 \mathrm{~min}$. Finally, samples were transferred to new containers under the same conditions as the initial one to assess the ability of the material to release fluoride ions continuously (7).

The concentration of fluoride ions released into deionized water was assessed by using a fluoride specific ion-electrode [Orion 9609BN, Orion Research Inc. United States] with a combination of digital ion-analyzer [Orion EA 940, Orion Research Inc. United States]. Calibration of the electrode was performed before measurement with standard solutions $(0.1$, 1,10 , and $100 \mathrm{ppm}$ fluoride). Then, fluoride ions measurements were conducted by adding $10 \mathrm{ml}$ of total ionic strength adjustment buffer II (TISAB II with CDTA, Orion 940909, USA) to each polyethylene vial to stabilize $\mathrm{pH}$ and to avoid the formation of complexes between the fluoride ions and different cations. Fluoride concentrations, expressed in ppm $(\mathrm{mg} / \mathrm{L})$, were displayed on the digital ion-analyzer.

After 63 days of immersion and fluoride release measurement, the samples were evaluated for the fluoride recharge capability. Samples were removed from the vials and immersed in $2 \%$ sodium fluoride gel (NaF; Sultan Topex neutral $\mathrm{pH}$, Sultan Health Care, Hackensack, NJ, USA, 9040 ppm Fluoride ion) for 4min (16) After the treatment, each sample was rinsed from both sides with deionized water for $20 \mathrm{sec}$ and dried on absorbent paper for $2 \mathrm{~min}$. Finally, the sample was returned to its vial containing $10 \mathrm{ml}$ of fresh deionized water. Again, fluoride re-release from each sample after fluoride recharge was similarly assessed at 1, 7, 14, 21, $28,35,42,49,56$ and 63 days.

\section{Statistical Analysis:}

Data were presented as means \pm standard deviation. Analysis of variance (ANOVA) was used to explore the effect of different coatings, materials and time on fluoride release and recharge. Following significant interactions, One-way ANOVA was conducted to further explore the effect of different coatings on fluoride release and recharge. Post-hoc comparisons using the Tukey's test was used to investigate differences between groups.

Independent sample t-test was conducted to explore the effect of materials on fluoride release and recharge. One-way repeated measure ANOVA was conducted to further explore the effect of time on fluoride release and recharge. Post-hoc comparisons using the Bonferroni test was used to investigate differences between groups. The significance level was set at $\mathrm{P} \leq$ 0.05 . Statistical analysis was computed using IBM ${ }^{\circledR}$ SPSS ${ }^{\circledR}$ Statistics version 24 for Mac (Armonk, NY: IBM Corp,USA).

\section{Results:}

\section{Fluoride Release}

Regarding the effect of coatings on fluoride release, results showed that application of coats on glass hybrid GIC resulted in a significant reduction in the concentration of fluoride ions 
released at all tested time intervals, in comparison to the control (uncoated) group, with significant differences observed between all of the tested subgroups $(p<0.0001)$. Where, the samples of glass hybrid GIC coated with nanofilled Forte coat and universal adhesive (subgroup 2 and 3: EF, EU) released the least concentration of fluoride ions at 7days, 21days, 35 days and 42 days. While, the vaseline-coated samples (EV) recorded higher amount of ions release. Moreover, the burst release of fluoride ions occurred at day 1 in all subgroups, except in vaseline-coated subgroup which was delayed to day 35. ANOVA showed that fluoride ions release diminished gradually with time, but maintained during the whole tested period with different values until recharge. Also, significant increase in the fluoride ions release was noted in all coated subgroups at day 21. (Table 2, Figure 1a)

For the RMGIC, results revealed that application of coats delayed the burst release till day 21, where the nano-filled Equia Forte coat subgroup (FF) recorded the least fluoride ions release. Following the burst release, ANOVA showed significant reduction of fluoride release $(\mathrm{p}<0.0001)$ which was maintained at constant level in all tested subgroups till the end of the study. Moreover, starting from the day 28, no significant difference was found between the uncoated subgroup and all other coated ones (Table 3, Figure 1b).

Regarding the effect of glass ionomer materials on the fluoride release, results showed that the uncoated glass hybrid GIC (Equia Forte Fil) released significantly higher concentration of fluoride ions at all tested time intervals than the uncoated RMGIC $(p<0.0001)$. However, after coating with any of the tested coating agents, the released fluoride ions from glass hybrid material were significantly lower than the RMGIC at all time period $(\mathrm{p}<0.0001)$. Also, both materials were able to maintain more or less constant fluoride release during nearly the last six weeks. (Figure 2)

Fluoride Recharge:

All the investigated groups in this study showed the ability to recharge with $\mathrm{NaF}$ gel and re-release again. Both materials; glass hybrid GIC and RMGIC exhibited the same pattern of fluoride re-release. Where, the uncoated samples released the highest amount of fluoride ions after 24 hours, while after coating with any of the tested coating agents the burst release was noticed after 7 days with the least amount of fluoride ions released was recorded in nano-filled Equia Forte coat and universal adhesive subgroups (EF,EU,FF,FU). Afterwards, a sharp drop in the fluoride concentrations was recorded, though a constant fluoride levels was maintained till the end of this study. (Tables $4 \& 5$, Figure 3 )

Regarding the effect of the materials, results revealed that the uncoated glass hybrid GIC released significantly higher fluoride levels than RMGIC. While no significant difference was found at day 1 and 28 ( $\mathrm{p}=0.19$ and 0.33 respectively). However, after coating, the glass hybrid released significantly lower fluoride than RMGIC at nearly all time intervals. No statistical difference was detected between both materials at day 14 and 42 in case of nano-filled Equia Forte coat ( $\mathrm{p}=0.17$ and 0.12 respectively) and universal adhesive-coated subgroups $(\mathrm{p}=0.078$ and 0.084 respectively), and at days 35 and 63 in vaseline-coated subgroups $(0.6$ and 0.1 respectively). (Figure 4)

According to the obtained results of the current study, the null hypothesis has been rejected.

\section{Discussion:}

Glass ionomer cements are the most widely used fluoride- releasing restorative materials in dentistry. Besides their multiple advantages, the fluoride release and recharging ability is of prime importance to prevent recurrent caries and demineralization of the tooth structure $(17,18)$.

Two types of GICs were used in this study; a recent glass hybrid self-set GIC (Equia Forte Fil) and light-cured RMGIC (Fuji II) to subsidiary evaluate the effect of curing method on fluoride ions release. Both types were supplied as capsules to avoid manipulative errors. Moreover, finishing and polishing of the samples was avoided to prevent changes in the materials' surface area (15). 
Table 1: Description of The Materials Used in The Study

\begin{tabular}{|c|c|c|c|}
\hline Commercial name & Material type & Chemical compositions & Manufacturer \\
\hline $\begin{array}{l}\text { Equia Forte Fil } \\
\text { (Shade A3) }\end{array}$ & $\begin{array}{l}\text { Glass Hybrid } \\
\text { Self-cure } \\
\text { glass-ionomer } \\
\text { cement }\end{array}$ & $\begin{array}{l}\text { Powder: } 95 \% \text { strontium } \\
\text { fluoroaluminosilicate glass and } 5 \% \\
\text { polyacrylic acid. } \\
\text { Liquid: } 40 \% \text { aqueous polyacrylic acid }\end{array}$ & $\begin{array}{l}(\# 1804242, \mathrm{GC} \\
\text { Corporation, Tokyo, } \\
\text { Japan) }\end{array}$ \\
\hline $\begin{array}{l}\text { GC Fuji II LC } \\
\text { (Shade A3) }\end{array}$ & $\begin{array}{l}\text { Light cured } \\
\text { Resin- } \\
\text { modified } \\
\text { glass-ionomer } \\
\text { cement }\end{array}$ & $\begin{array}{l}\text { Powder 100\% Alumino-fluoro-silicate glass } \\
\text { Liquid 20-22\% Polyacrylic acid, 30- } 40 \% \\
\text { 2-Hydroxyethyl methacrylate (HEMA), 5- } \\
\text { 7\% Trimethyl hexamethylene dicarbonate, } \\
\text { 4-6\% Triethylene glycol dimethacrylate, } \\
<10 \% \text { Urethane dimethacrylate, Initiator, } \\
<1 \% \text { Camphroquinone }\end{array}$ & $\begin{array}{l}\text { (\#1806213 GC } \\
\text { Corporation, Tokyo, } \\
\text { Japan) }\end{array}$ \\
\hline Equia Forte Coat LC & $\begin{array}{l}\text { Nanofilled } \\
\text { self- adhesive } \\
\text { light- cured } \\
\text { protective } \\
\text { coating }\end{array}$ & $\begin{array}{l}40 \%-50 \% \text { methyl methacrylate, } 10 \%-15 \% \\
\text { colloidal silica, } 0.09 \% \text { camphorquinone, } \\
30 \%-40 \% \text { urethane methacrylate, } 1 \%-5 \% \\
\text { phosphoric ester monomer }\end{array}$ & $\begin{array}{l}\text { (\#180515A, GC } \\
\text { Corporation, Tokyo, } \\
\text { Japan) }\end{array}$ \\
\hline $\begin{array}{l}\text { Single bond } \\
\text { Universal }\end{array}$ & Adhesive & $\begin{array}{l}\text { 10-methacryloyloxydecyl dihydrogen } \\
\text { phosphate monomer (10-MDP), HEMA, } \\
\text { Bisphenol A- Glycidyl Methacrylate } \\
\text { (BisGMA), Dimethacrylate (DMA), } \\
\text { photoinitiator, polyacrylic acid copolymer, } \\
\text { itaconic acid, silane, water, ethanol }\end{array}$ & $\begin{array}{l}\text { (\#510450, 3M ESPE, } \\
\text { Germany) }\end{array}$ \\
\hline Petroleum jelly & Vaseline & petrolatum & $\begin{array}{l}\text { (\# M.L.No.M-PP/ 5498/98 } \\
\text { Hindustan Lever Ltd, } \\
\text { Unilever, India) }\end{array}$ \\
\hline
\end{tabular}
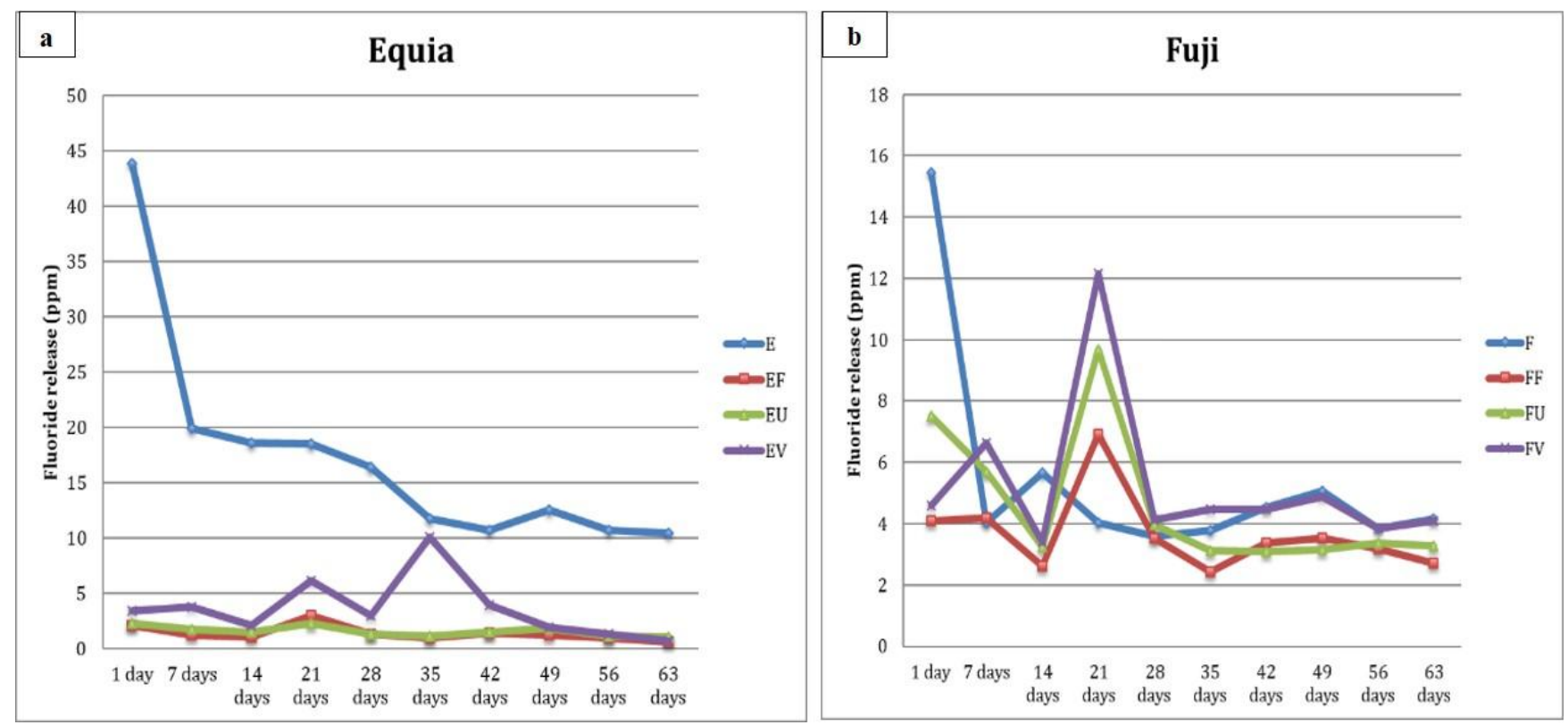

Figure 1: Mean values for fluoride ions released ( $\mathrm{ppm}$ ) over time from the different subgroups of (a): glass hybrid GIC (E=Equia without coat, $\mathrm{EF}=$ Equia+ Forte coat, $\mathrm{EU}=$ Equia+ Universal adhesive and $\mathrm{EV}=$ Equia+ Vaseline) and (b): resin modified GIC ( $\mathrm{F}=\mathrm{Fuji}$ II without coat, $\mathrm{FF}=\mathrm{Fuji}$ II+ Forte coat, $\mathrm{FU}=$ Fuji II+ universal adhesive and FV= Fuji II+ Vaseline) 
Table 2: The mean \pm standard deviation (SD) of fluoride ions release (in ppm) from the different subgroups of glass hybrid GIC (Equia Forte Fil) at different time intervals

\begin{tabular}{|c|c|c|c|c|c|}
\hline \multicolumn{6}{|c|}{ Equia, Fluoride release (ppm) } \\
\hline \multirow[t]{3}{*}{ Time } & \multicolumn{4}{|c|}{ Coating } & \multirow[t]{3}{*}{ P-value } \\
\hline & No coat $(E)$ & Forte coat $(\mathbf{E F})$ & Universal (EU) & Vaseline (EV) & \\
\hline & Mean ( $( \pm S D)$ & Mean $( \pm \mathrm{SD})$ & Mean $( \pm \mathrm{SD})$ & Mean $( \pm$ SD) & \\
\hline 1 day & $43.85(3.851)^{\mathrm{aA}}$ & $2.067(0.843)^{\mathrm{bAB}}$ & $2.25(0.442)^{\mathrm{bA}}$ & $3.4(1.671)^{\mathrm{bCD}}$ & 0.0001 \\
\hline 7 days & $19.867\left(2.573^{\mathrm{aB}}\right.$ & $1.2(0.341)^{\mathrm{cBC}}$ & $1.75(0.493)^{\mathrm{bcAB}}$ & $3.783(1.376)^{\mathrm{bCD}}$ & 0.0001 \\
\hline 14 days & $18.55(2.705)^{\mathrm{aB}}$ & $1(0.518)^{\mathrm{bBC}}$ & $1.467(0.273)^{\mathrm{bAB}}$ & $2.033(1.069)^{\mathrm{bCDEF}}$ & 0.0001 \\
\hline 21 days & $18.45(1.608)^{\mathrm{aB}}$ & $2.95(1.269)^{\mathrm{cA}}$ & $2.233(0.619)^{\mathrm{cA}}$ & $6.083(0.979)^{\mathrm{bB}}$ & 0.0001 \\
\hline 28 days & $16.417(3.709)^{\mathrm{aBC}}$ & $1.283(0.534)^{\mathrm{bBC}}$ & $1.267(0.242)^{\mathrm{bB}}$ & $2.933(0.602)^{\mathrm{bCDE}}$ & 0.0001 \\
\hline 35 days & $11.717(3.449)^{\mathrm{aCD}}$ & $0.967(0.234)^{\mathrm{bBC}}$ & $1.083(0.306)^{\mathrm{bB}}$ & $10.1(1.378)^{\mathrm{aA}}$ & 0.0001 \\
\hline 42 days & $10.717(2.33)^{\mathrm{aD}}$ & $1.333(0.582)^{\mathrm{cBC}}$ & $1.433(0.547)^{\mathrm{cAB}}$ & $3.933(0.857)^{\mathrm{bC}}$ & 0.0001 \\
\hline 49 days & $12.533(1.54)^{\mathrm{aCD}}$ & $1.183(0.24)^{\mathrm{BBC}}$ & $1.833(0.635)^{\mathrm{bAB}}$ & $1.917(0.538)^{\mathrm{bDEF}}$ & 0.0001 \\
\hline 56 days & $10.7(1.468)^{\mathrm{aD}}$ & $0.933(0.288)^{\mathrm{bBC}}$ & $1.1(0.424)^{\mathrm{bB}}$ & $1.317(0.382)^{\mathrm{bEF}}$ & 0.0001 \\
\hline 63 days & $10.4(0.951)^{\mathrm{aD}}$ & $0.55(0.243)^{\mathrm{bC}}$ & $1(0.179)^{\mathrm{bB}}$ & $0.633(0.55)^{\mathrm{bF}}$ & 0.0001 \\
\hline P-value & 0.0001 & 0.009 & 0.007 & 0.0001 & \\
\hline
\end{tabular}

Different small letters indicate significant difference within the same row for every time period.

Different Capital letters indicates significant difference within the same column for every coat type.

Table 3: The mean \pm standard deviation (SD) of fluoride ions release (in $\mathrm{ppm}$ ) from the different subgroups of resin-modified GIC (Fuji II) at different time intervals

\begin{tabular}{|c|c|c|c|c|c|}
\hline \multicolumn{6}{|c|}{ Fuji II, Fluoride release (ppm) } \\
\hline \multirow[t]{3}{*}{ Time } & \multicolumn{4}{|c|}{ Coating } & \multirow[t]{3}{*}{ P-value } \\
\hline & No coat $(\mathbf{F})$ & Forte coat $(\mathrm{FF})$ & Universal (FU) & Vaseline (FV) & \\
\hline & Mean $( \pm$ SD) & Mean $( \pm \mathrm{SD})$ & Mean $( \pm \mathrm{SD})$ & Mean $( \pm S D)$ & \\
\hline 1 day & $15.45(4.543)^{\mathrm{aA}}$ & $4.1(0.982)^{\mathrm{bB}}$ & $7.517(2.038)^{\mathrm{bB}}$ & $4.6(1.171)^{\mathrm{bBC}}$ & 0.0001 \\
\hline 7 days & $4.033(0.273)^{\mathrm{bB}}$ & $4.183(0.842)^{\mathrm{bB}}$ & $5.7(1.463)^{\mathrm{abBC}}$ & $6.65(1.365)^{\mathrm{aB}}$ & 0.001 \\
\hline 14 days & $5.667(0.826)^{\mathrm{aB}}$ & $2.633(0.787)^{\mathrm{bB}}$ & $3.233(0.612)^{\mathrm{bD}}$ & $3.417(0.882)^{\mathrm{bC}}$ & 0.0001 \\
\hline 21 days & $4.017(1.026)^{\mathrm{dB}}$ & $6.917(1.061)^{\mathrm{cA}}$ & $9.667(0.911)^{\mathrm{bA}}$ & $12.167(2.305)^{\mathrm{aA}}$ & 0.0001 \\
\hline 28 days & $3.6(1.018)^{\mathrm{aB}}$ & $3.533(0.692)^{\mathrm{aB}}$ & $3.967(0.459)^{\mathrm{aCD}}$ & $4.117(0.631)^{\mathrm{aC}}$ & 0.458 \\
\hline 35 days & $3.783(0.549)^{\mathrm{abB}}$ & $2.417(0.483)^{\mathrm{cB}}$ & $3.117(0.585)^{\mathrm{bcD}}$ & $4.467(0.969)^{\mathrm{aBC}}$ & 0.0001 \\
\hline 42 days & $4.533(0.68)^{\mathrm{aB}}$ & $3.367(0.937)^{\mathrm{abB}}$ & $3.083(0.471)^{\mathrm{bD}}$ & $4.467(0.797)^{\mathrm{aBC}}$ & 0.004 \\
\hline 49 days & $5.067(0.609)^{\mathrm{aB}}$ & $3.517(1.533)^{\mathrm{aB}}$ & $3.167(0.944)^{\mathrm{aD}}$ & $4.867(1.424)^{\mathrm{aBC}}$ & 0.053 \\
\hline 56 days & $3.85(0.622)^{\mathrm{aB}}$ & $3.2(0.865)^{\mathrm{aB}}$ & $3.383(0.412)^{\mathrm{aD}}$ & $3.833(1.127)^{\mathrm{aC}}$ & 0.417 \\
\hline 63 days & $4.15(0.409)^{\mathrm{aB}}$ & $2.717(0.915)^{\mathrm{bB}}$ & $3.283(0.366)^{\mathrm{abD}}$ & $4.1(0.253)^{\mathrm{aC}}$ & 0.0001 \\
\hline P-value & 0.001 & 0.0001 & 0.0001 & 0.0001 & \\
\hline
\end{tabular}

Different small letters indicate significant difference within the same row for every time period.

Different Capital letters indicates significant difference within the same column for every coat type. 

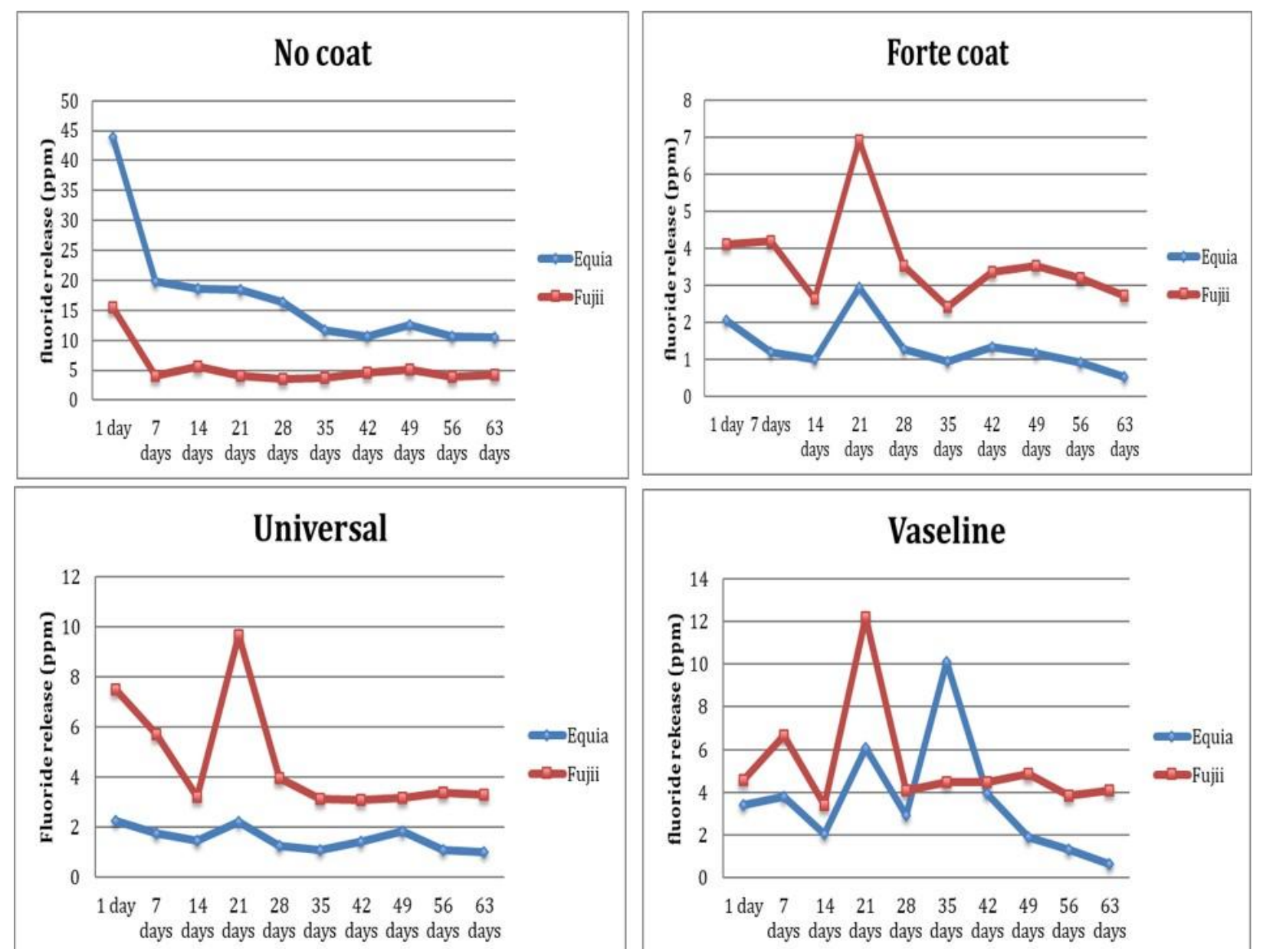

Figure 2: Fluoride ions released (ppm) over time from the different glass ionomer materials; glass hybrid GIC (Equia Forte Fil) and resin modified GIC (Fuji II) in the different subgroups.

Table 4: The mean \pm standard deviation (SD) of fluoride ions release in ppm from the different subgroups of glass hybrid GIC (Equia Forte Fil) at different time intervals after fluoride recharging with NaF gel

\begin{tabular}{|c|c|c|c|c|c|}
\hline \multicolumn{6}{|c|}{ Equia, Fluoride recharge (ppm) } \\
\hline \multirow[t]{3}{*}{ Time } & \multicolumn{4}{|c|}{ Coating } & \multirow[t]{3}{*}{ P-value } \\
\hline & No coat $(E)$ & Forte coat $(\mathrm{EF})$ & Universal (EU) & Vaseline (EV) & \\
\hline & Mean $( \pm \mathrm{SD})$ & Mean $( \pm$ SD) & Mean $( \pm$ SD) & Mean $( \pm \mathrm{SD})$ & \\
\hline 1 day & $16.917(3.899)^{\mathrm{aA}}$ & $2.117(0.417)^{\mathrm{bC}}$ & $2.133(0.301)^{\mathrm{bCD}}$ & $2.883(0.649)^{\mathrm{bC}}$ & 0.0001 \\
\hline 7 days & $10.783(3.996)^{\mathrm{aB}}$ & $6.217(1.512)^{\mathrm{bA}}$ & $6.117(1.855)^{\mathrm{bA}}$ & $7.783(1.826)^{\mathrm{abA}}$ & 0.014 \\
\hline 14 days & $10.05(4.303)^{\mathrm{aB}}$ & $4.217(0.662)^{\mathrm{bB}}$ & $4.567(0.668)^{\mathrm{bB}}$ & $4.983(0.768)^{\mathrm{bB}}$ & 0.001 \\
\hline 21 days & $8.333(3.244)^{\mathrm{aBC}}$ & $1.1(0.424)^{\mathrm{bCDE}}$ & $1.35(0.418)^{\mathrm{bCDE}}$ & $1.55(0.414)^{\mathrm{bCDE}}$ & 0.0001 \\
\hline 28 days & $6.117(2.143)^{\mathrm{aBCD}}$ & $1.55(0.327)^{\mathrm{bCD}}$ & $2.5(0.672)^{\mathrm{bC}}$ & $2.233(0.698)^{\mathrm{bCD}}$ & 0.0001 \\
\hline 35 days & $6.133(1.288)^{\mathrm{aBCD}}$ & $0.567(0.388)^{\mathrm{cDE}}$ & $0.85(0.423)^{\mathrm{cDE}}$ & $2.867(1.424)^{\mathrm{bC}}$ & 0.0001 \\
\hline 42 days & $4.083(1.083)^{\mathrm{aCD}}$ & $0.9670 .308)^{\mathrm{bDE}}$ & $1.05(0.362)^{\mathrm{bDE}}$ & $1.233(0.427)^{\mathrm{bCDE}}$ & 0.0001 \\
\hline 49 days & $3.017(0.924)^{\mathrm{aD}}$ & $0.9(0.352)^{\mathrm{bDE}}$ & $0.52(0.457)^{\mathrm{bE}}$ & $1.1(0.405)^{\mathrm{bDE}}$ & 0.0001 \\
\hline 56 days & $1.55(0.373)^{\mathrm{aD}}$ & $0.09(0.061)^{\mathrm{bE}}$ & $0.333(0.312)^{\mathrm{bE}}$ & $0.45(0.483)^{\mathrm{bE}}$ & 0.0001 \\
\hline 63 days & $1.3(0.415)^{\mathrm{aD}}$ & $0.055(0.034)^{\mathrm{bE}}$ & $0.38(0.521)^{\mathrm{bE}}$ & $0.508(0.344)^{\mathrm{bE}}$ & 0.0001 \\
\hline P-value & 0.0001 & 0.0001 & 0.0001 & 0.0001 & \\
\hline
\end{tabular}

Different small letters indicate significant difference within the same row for every time period. Different Capital letters indicates significant difference within the same column for every coat type. 

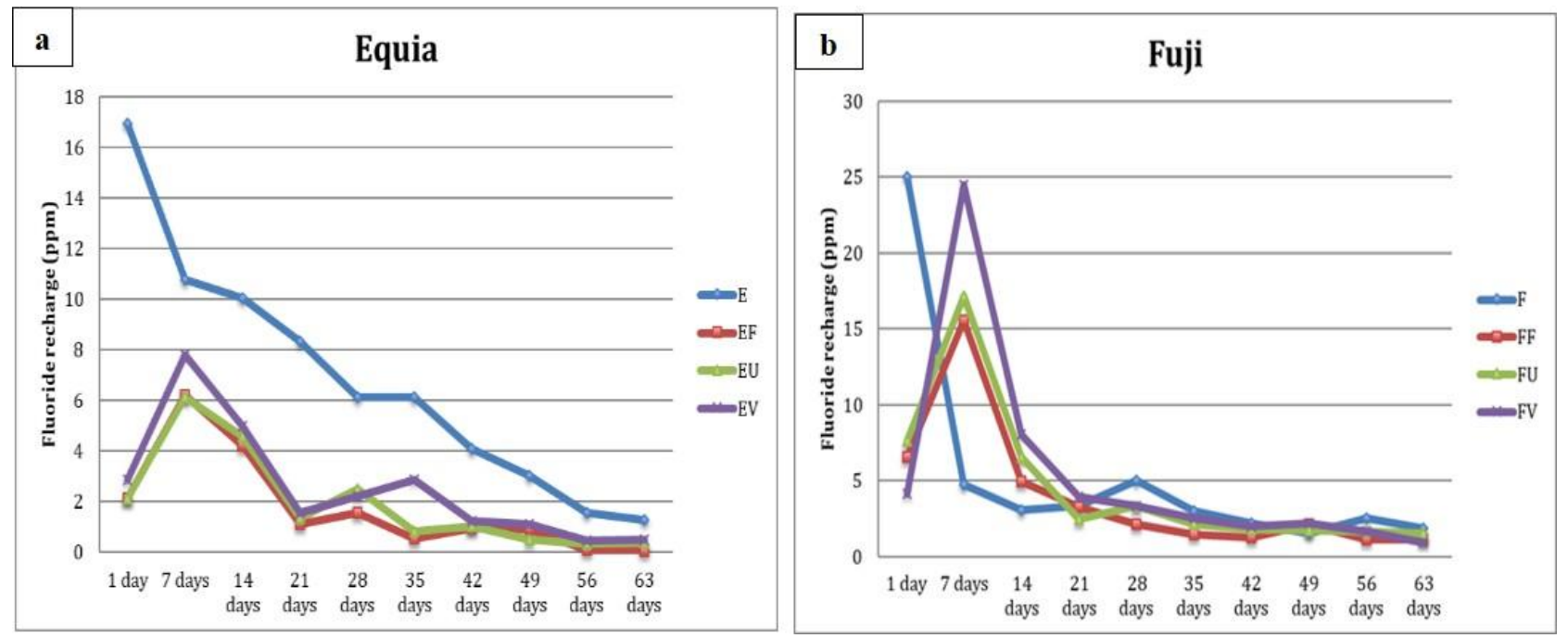

Figure 3: Mean values for fluoride ions released (ppm) over time from the different subgroups of (a): glass hybrid GIC (E=Equia without coat, $\mathrm{EF}=$ Equia+ Forte coat, $\mathrm{EU}=$ Equia+ universal adhesive and $\mathrm{EV}=$ Equia+ Vaseline) and (b): resin modified GIC (F=Fuji II without coat, FF= Fuji II + Forte coat, $\mathrm{FU}=$ Fuji II + universal adhesive and FV= Fuji II + Vaseline) after fluoride recharging
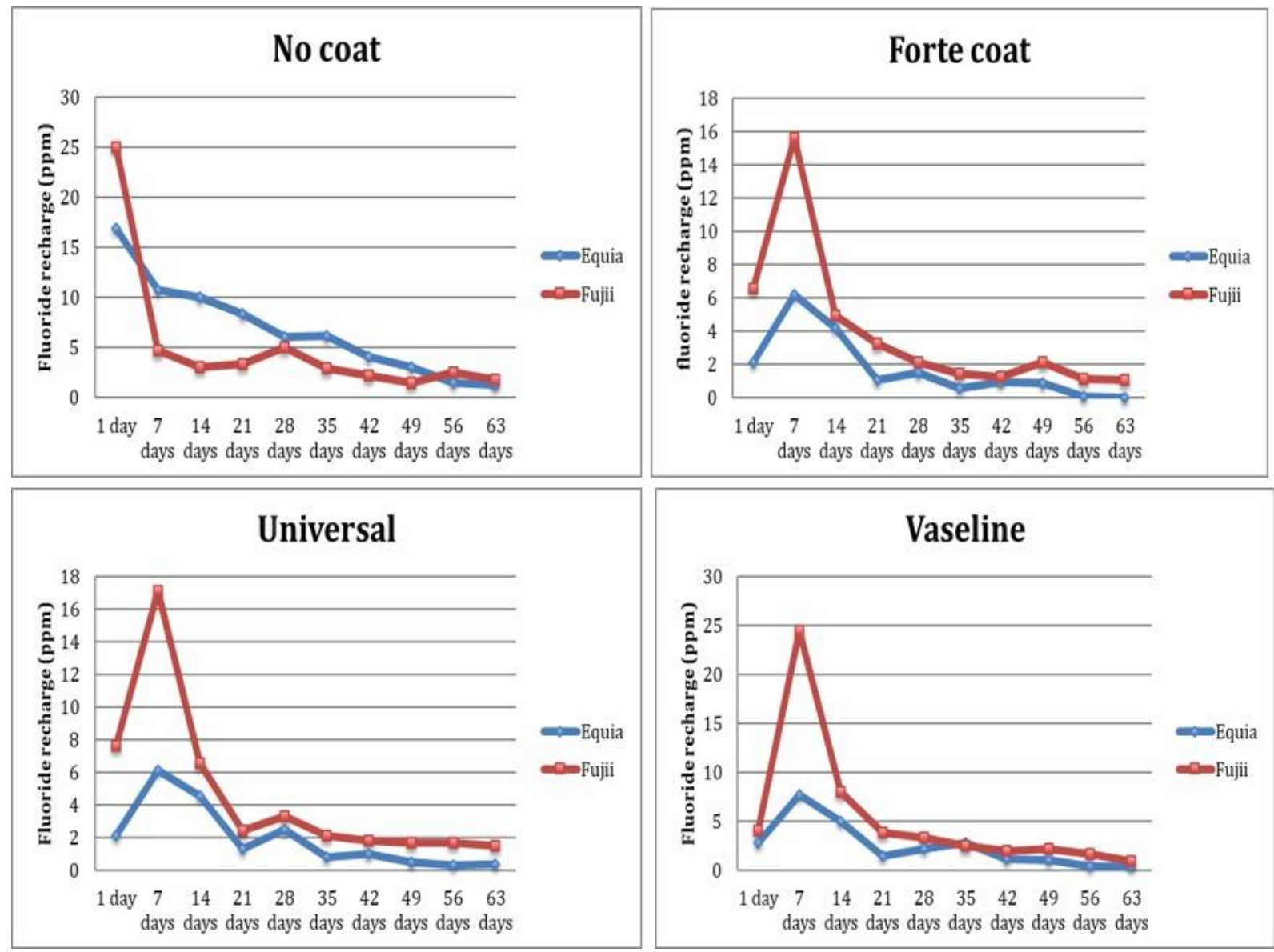

Figure 4: Fluoride ions released (ppm) over time from the different glass ionomer materials; glass hybrid GIC (Equia Forte Fil) and resin modified GIC (Fuji II) in the different subgroups after fluoride recharging. 
Table 5: The mean \pm standard deviation (SD) of fluoride ions release (in ppm) from the different subgroups of resin-modified GIC (Fuji II) at different time intervals after fluoride recharging with NaF gel

\begin{tabular}{|c|c|c|c|c|c|}
\hline \multicolumn{6}{|c|}{ Fuji II, Fluoride recharge (ppm) } \\
\hline \multirow[t]{3}{*}{ Time } & \multicolumn{4}{|c|}{ Coating } & \multirow[t]{3}{*}{ P-value } \\
\hline & No coat $(F)$ & Forte coat (FF) & Universal (FU) & Vaseline (FV) & \\
\hline & Mean $( \pm \mathrm{SD})$ & Mean $( \pm \mathrm{SD})$ & Mean $( \pm \mathrm{SD})$ & Mean $( \pm \mathrm{SD})$ & \\
\hline 1 day & $24.983(5.933)^{\mathrm{aA}}$ & $6.567(2.639)^{\mathrm{bB}}$ & $7.6(2.666)^{\mathrm{bB}}$ & $4.133(0.761)^{\mathrm{bC}}$ & 0.0001 \\
\hline 7 days & $4.717(1.447)^{\mathrm{cB}}$ & $15.583(4.313)^{\mathrm{bA}}$ & $17.133(5.451)^{\mathrm{bA}}$ & $24.483(3.804)^{\mathrm{aA}}$ & 0.0001 \\
\hline 14 days & $3.05(0.524)^{\mathrm{cB}}$ & $4.95(1.021)^{\mathrm{bcBC}}$ & $6.55(2.386)^{\mathrm{abBC}}$ & $8.067(2.731)^{\mathrm{aB}}$ & 0.001 \\
\hline 21 days & $3.35(1.241)^{\mathrm{abB}}$ & $3.283(0.44)^{\mathrm{abCD}}$ & $2.483(0.337)^{\mathrm{bD}}$ & $3.917(0.703)^{\mathrm{aCD}}$ & 0.032 \\
\hline 28 days & $5(1.599)^{\mathrm{aB}}$ & $2.117(0.83)^{\mathrm{bCD}}$ & $3.333(0.35)^{\mathrm{bCD}}$ & $3.35(0.644)^{\mathrm{bCD}}$ & 0.001 \\
\hline 35 days & $3(0.959)^{\mathrm{aB}}$ & $1.483(0.538)^{\mathrm{bD}}$ & $2.133(0.258)^{\mathrm{abD}}$ & $2.517(0.76)^{\mathrm{abCD}}$ & 0.007 \\
\hline 42 days & $2.2(0.469)^{\mathrm{aB}}$ & $1.283(0.343)^{\mathrm{bD}}$ & $1.817(0.852)^{\mathrm{abD}}$ & $2.017(0.232)^{\mathrm{abCD}}$ & 0.039 \\
\hline 49 days & $1.5(0.385)^{\mathrm{aB}}$ & $2.133(0.674)^{\mathrm{aCD}}$ & $1.7(0.303)^{\mathrm{aD}}$ & $2.2(0.576)^{\mathrm{aCD}}$ & 0.075 \\
\hline 56 days & $2.517(0.608)^{\mathrm{aB}}$ & $1.15(0.327)^{\mathrm{bD}}$ & $1.683(0.382)^{\mathrm{bD}}$ & $1.683(0.313)^{\mathrm{bCD}}$ & 0.0001 \\
\hline 63 days & $1.833(0.372)^{\mathrm{aB}}$ & $1.1(0.335)^{\mathrm{bD}}$ & $1.517(0.319)^{\mathrm{abD}}$ & $0.95(0.489)^{\mathrm{bD}}$ & 0.003 \\
\hline P-value & 0.0001 & 0.0001 & 0.001 & 0.0001 & \\
\hline
\end{tabular}

Different small letters indicate significant difference within the same row for every time period. Different Capital letters indicates significant difference within the same column for every coat type.

Fluoride release could be evaluated in saliva or $\mathrm{pH}$ cycling solutions in order to mimic the oral environment. However, in the current study, the deionized water was selected as storage medium as it contains no fluoride traces or minerals and thus can accurately indicates the fluoride ions release from GICs $(19,20)$.

According to Arbabzadeh-Zavareh $\mathrm{F}$ et al. (21), exhaustion of the materials from fluoride ion release could occur after 60 s day. Thus, the authors considered fluoride release either before or after recharging at different time intervals, starting from 1 day then weekly till 63 days. It is worthy to mention that some investigators reported the capability of GIC to release fluoride up to 5 years at a constant rate (22).

It is crucial to apply coating on the surface of GICs as the setting reaction proceeds slowly after the initial hardening is complete for preservation of the labile water present in the cement and prevent its loss that lead to microcracks development and chalky appearance. At the same time, the restoration should be protected against moisture attack with subsequent washing out of the cement matrix and loss of translucency and deterioration of physical properties $(3,23)$.
In the current study, two light-cured coats were used; a recently introduced nano-filled Equia Forte coat and the commonly used single bond universal adhesive, as well the traditional petroleum jelly (Vaseline). It was reported that light-curable coats are preferred over simple varnish as they could protect GIC more effectively from dehydration or water uptake, and that they ameliorate the physical properties of the restorations (24).

The present study showed that coating of either material; glass hybrid GIC or RMGIC, with any of the tested coating agents resulted in a dramatic decrease in the fluoride ions release at all time periods $(p<0.0001)$ and the decrease was much more pronounced in glass hybrid GIC. This result was in accordance with other studies $(25,26)$ that reported $60-76 \%$ reduction in fluoride release after coating of GICs. It was suggested that the coats prevented the dissolution of the superficial layer of immature GIC. In addition,) the surface coat could represent a barrier that restrict but not eliminate the fluoride release (27).

Regarding the type of coat, results showed that the type of coat affected the amount of 
fluoride released from both investigated GI cements. The vaseline-coated samples released significantly more fluoride from both materials, denoting that Equia Forte nano-filled coat and universal adhesive were able to seal the GICs surface more effectively. This was in agreement with the findings of Kishore GVS et al (28) who found that application of vaseline or G-Coat Plus significantly inhibited the fluoride ions release. But, this inhibition was more pronounced in the G-Coat Plus group. They referred this result to the snip in the water movement. G-Coat Plus (nano-filled) could prevent the superficial washout and diffusion via pores, leading to decrease in fluoride ions release as reported by Tiwari $\mathrm{S}$ and Nandlal B (25).

The results of the present study revealed a statistically significant difference between the self- cure glass hybrid GIC and light cured RMGIC before and after coating. Without coating, the glass hybrid Equia Forte Fil released significantly higher fluoride ions than RMGIC. This could be attributed to the composition of this cement type; Table (1), as the substitution of $\mathrm{Ca} 2+$ with $\mathrm{Sr} 2+$ ions improved the fluoride release rate due to faster dissociation of strontium fluoride complex ( $\mathrm{SrF} 2)$ than calcium fluoride complex (CaF2) (29). However, the pattern of fluoride release from the uncoated RMGIC is in line with other investigation (27), that recorded an initial burst release followed by a slow rate of release. This might be referred to the acid-base reaction that takes place at the first 24 hours and results in fluoride ions dissociation.

Moreover, the curing methods could greatly affect the fluoride release from GICs. The light activated polymerizations increases cross-linking density and thus decreases the matrix permeability to release fluoride ions. $(30,31)$. This might explain the lower fluoride ions released from the RMGIC (FujiII); Table (3). In contrast, Jafari $\mathrm{K}$ et al (15) recorded higher fluoride release from Fuji II GIC in comparison to Equia Forte Fil GIC coated with Equia coat. They explained their findings on the basis of the slow acid-base reaction of the former that render the ionic matrix less mature and more porous; thus, increased the fluoride release of RMGIC. However, the difference in methodology could explain the variation in results, as in the previous study the Equia coat was only applied onto the Equia Forte Fil GIC while the RMGIC was left uncoated.

Meanwhile, in case of RMGIC, the results revealed insignificant difference between the uncoated subgroup and all the coated subgroups starting approximately from the 4th week; Table (3). Momoi Y and McCabe JF (32) found that the amount and type of resin present in the cement could affect the rate of fluoride release. Thus, the presence of HEMA in the RMGIC enable the cement to absorb water which facilitates the diffusion and release of fluoride ions instead of kept encapsulated in the polyacrylate matrix. Besides, the hydrophilicity and low viscosity of the coatings could be another contributing factors that allowed the fluoride release from the material. It was stated that the adhesive has the ability to act as permeable membranes after polymerization, permitting the diffusion of fluoride to and from the GIC (33).

It should be pointed that the mechanism of fluoride release from GIC takes place mainly by the following steps: surface loss, diffusion via materials' cracks and pores, then bulk diffusion (34). Although the results of this study showed variation in the fluoride ions concentrations among the different subgroups of each tested material, yet, they all followed the same pattern of ion release. A significantly high concentration of fluoride ions was released either at day 1 or delayed in some groups, then a subsequent sharp drop was detected in the following days. The delay reported in the vaseline-coated subgroup could be related to its dissolution.

The initial highest level of ion release might be attributed to surface wash step, known as burst effect. During the setting reaction, the polyacrylic acid attack the glass fillers' surfaces leading to fast dissolution and release of a significantly large concentration of fluoride ions into the surrounding media $(34,35)$. However, the drop of the fluoride levels that occurred in the subsequent days might be caused by the 
slower particles dissolution and release through the materials' pores. Meanwhile, the monitored re-increase that was observed after the drop could be related to the bulk diffusion that takes place during the maturation phase due to contact between; glass ionomer cement and the storage medium (34).

It was found that the burst release is advantageous and highly required to prevent caries and demineralization of the tooth structure, also the sustained ions release increase the resistance of tooth structure to further carious attacks (36). Unfortunately, the low levels of fluoride release that occurs after the burst release could be insufficient to prevent secondary caries. Therefore, the fluoride recharge and re-release capability of the material become very important property especially in patient with high caries index.

All the investigated groups in this study showed the ability to recharge with $\mathrm{NaF}$ gel and re-release again. Logically, the uncoated samples of both GI materials released the highest amount of fluoride after 24 hours, while after coating the burst release was recorded after day 7; Tables $(4 \& 5)$. The results also revealed that the uncoated glass hybrid GIC released significantly higher fluoride levels than RMGIC, but after coating application a significant decrease in the fluoride re-release was recorded at nearly all time intervals when compared with RMGIC groups. The low fluoride re-release of glass hybrid GIC could be attributed to the saturation effect hypothesized by Freedman $\mathrm{R}$ and Diefinderfer KE (37), as the GICs have not the ability to uptake more fluoride at a certain point. This was confirmed by the low fluoride release of these coated samples prior to recharge; Table (2).

However, Takahashi $\mathrm{K}$ et al (38) reported that RMGIC were able to release fluoride ions effectively after $\mathrm{NaF}$ solutions applications. This was attributed to the fluoride ions infiltration into the cement's matrix rather than its adsorption on the surface. In fact, the recharging and re-release of fluoride ions from GIC rely to a great extent on the hydrogel layer structure surrounding the glass particles. Also, the permeability and porosity of GIC are crucial for the recharging ability of the material $(34,39,40,41)$.

It should be mentioned that the results of the current study indicated that the materials or groups with high level of fluoride release showed an increased recharging capability, which was in accordance with the findings of other investigators $(20,40)$. As well, the results showed a significant difference in the fluoride release/recharge ability between the two selected GICs and between different applied coats. Thus, the null hypothesis could not be accepted.

Conclusions:

Within the study limitations, the following conclusions could be drawn:

Though the application of coatings is mandatory on the GIC to protect against hydration and dehydration and to provide adequate seal, they have dramatic reducing effect in terms of fluoride ions release either before or after recharging.

The nano-filled coating as well as the universal adhesive have a hindering influence on the fluoride ions release from the GIC materials more than traditionally used petroleum jelly.

The effect of coating, especially the nanofilled coating, on the GIC is much more evident on the glass hybrid GIC than on RMGIC. Yet, all the coating agents maintained the fluoride release and recharging ability till the end of the study.

The application of the coatings on glass hybrid GIC and RMGIC delayed the burst release but it maintained the fluoride release ability of GICs at a constant level throughout the tested time periods.

\section{Conflict of Interest:}

The authors declare no conflict of interest.

\section{References:}

1. Petersen PM, Bourgeois D, Ogawa H, Estupinan Day S, Ndiaye C. The global burden of oral diseases and risks to oral health. Bull World Health Organ. 2005; 83:661-9.

2. Zafar MS, Ahmed N. Therapeutic roles of fluoride released from restorative dental materials. Fluoride. 2015; 48:184-94. 
3. Kamatham R, Reddy SJ. Surface coatings on GIC restorations in pediatric dentistry-Worthy or not? J Indian Soc Pedod Prev Dent. 2013; 31:229-33.

4. Davidson CL. Advances in glass-ionomer cements. J Appl Oral Sci. 2006;14 Suppl:3-9.

5. Wilson AD. Developments in glass-ionomer cements. Int J Prosthodont 1989; 2:438-46.

6. Gurgan S, Kutuk Z, Ergin E, Oztas S, Cakir F. Four year randomized clinical trial to evaluate the clinical performance of a glass ionomer restorative system. Oper Dent 2015; 40: 134-43.

7. Brzović Rajić V, Miletić I, Gurgan S, Peroš K, Verzak Ž, Malčić AI: Fluoride release from glass ionomer with nano filled coat and varnish. Acta Stomatol Croat. 2018;52(4):307-13.

8. Schwendicke F, Kniess J, Paris S, Blunck U. Margin integrity and secondary caries of lined or non-lined composite and glass hybrid restorations after selective excavation in vitro. Oper Dent 2016; 4, 41-6.

9. Sakr N A, Niazy MA, Gad NA. Evaluation of Fracture resistance of Some Contemporary Class II Glass Ionomer restorations at different time Intervals. ADJ-for Girls. 2019; 6(1): 45-51.

10. Diem VTK, Tyas MJ, Hien CN, Phuong LH, Khanh ND. The effect of a nano-filled resin coating on the 3-year clinical performance of a conventional high-viscosity glass-ionomer cement. Clin Oral Investig. 2014;18(3):753-9.

11. Lohbauer U, Kramer N, Siedschlag G, Schubert EW, Lauerer B, Muller FA, Petschelt A, Ebert J. Strength and wear resistance of a dental glassionomer cement with a novel nanofilled resin coating. Am J Dent. 2011;24(2):124-8.

12. Nicholson JW, Czarnecki B. Kinetic studies of the effect of varnish on water loss by glassionomer cements. Dent Mater. 2007; 23(12): 1549-52.

13. Leirskar J, Nordbo H, Mount GJ, Ngo H. The influence of resin coating on the punch shear strength of a high strength auto-cure glass ionomer. Dent Mater. 2003; 19(2): 87-91.

14. Rao A, Rao A, Sudha P. Fluoride rechargability of a non-resin auto-cured glass ionomer cement from a fluoridated dentifrice: An in vitro study. J Indian Soc Pedod Prev Dent. 2011;29(3):202-4.
15. Jafari K, Hoseini S, Hekmatfar S. Comparative evaluation of the fluoride recharge ability of two glass ionomers obtained from fluoridated dentifrice and CPP-ACFP paste: An in-vitro study. Dent Mater Tech 2019; 8(1): 45-51.

16. . Kucukyilmaz E, Savas S, Kavrik F, Yasa B, Botsali MS. Fluoride release/recharging ability and bond strength of glass ionomer cements to sound and caries-affected dentin. Nig J Clin Pract. 2017; 20(2): 226-34.

17. Petersen PE, Lennon MA. Effective use of fluorides for the prevention of dental caries in the 21st century: the WHO approach. Community Dent Oral Epidemiol. 2004; 32(5): 319-21.

18. Klai S, Altenburger M, Spitzmüller B, Anderson A, Hellwig E, Al-Ahmad A. Antimicrobial effects of dental luting glass ionomer cements on streptococcus mutants. Sci World. J. 2014; 2: 807086.

19. Karantakis $\mathrm{P}$, Helvatjoglou-Antoniades $\mathrm{M}$, Theodoridou-Pahini S, Papadogiannis Y. Fluoride release from three glass ionomers, a compomer, and a composite resin in water, artificial saliva, and lactic acid. Oper Dent 2000; 25:20-5.

20. Dionysopoulos D, Koliniotou-Koumpia E, Helvatzoglou-Antoniades M, Kotsanos N. Fluoride release and recharge abilities of contemporary fluoride-containing restorative materials and dental adhesives. Dent Mater J 2013; 32:296-304.

21. Arbabzadeh-Zavareh F, Gibbs T, Meyers IA, Bouzari M, Mortazavi S, Walsh LJ. Recharge pattern of contemporary glass ionomer restoratives. Dent Res J (Isfahan). 2012;9(2):139-45.

22. Luo J, Billington RW, Pearson GJ. Kinetics of fluoride release from glass components of glass ionomers. J Dent. 2009;37(7):495-501.

23. Hattab FN, Amin WM. Fluoride release from GIC restorative materials and the effects of surface coating. Biomaterials. 2001; 22:1449-58.

24. Earl MS, Mount GJ, Hume WR. Effect of varnishes and other surface treatments on water movement across the glass-ionomer cement surface.II. Aust Dent J. 1989;34(4):326-9.

25. Tiwari S, Nandlal B. Effect of nano-filled surface coating agent on fluoride release 
from conventional glass ionomer cement: An in vitro trial. J Indian Soc Pedod Prev Dent 2013;31:91-5.

26. McKnight-Hanes C, Whitford GM. Fluoride release from three glass ionomer materials and the effects of varnishing with or without finishing. Caries Res.1992;26(5):345-50.

27. Wang L, Buzalaf M A R, Atta MT: Effect of onebottle adhesive systems on the fluoride release of a resin-modified glass ionomer. J Appl Oral Sci 2004; 12(1): 12-7

28. Kishore GVS, Sai-Sankar AJ, Pratap-Gowd MJS, Sridhar M, Pranitha K, Sai-Krishna VS. Comparative evaluation of fluoride releasing ability of various restorative materials after the application of surface coating agents - an invitro study. J Clin Diagnos Res. 2016; 10(12): ZC38-ZC41

29. Moreau JL, Xu HH. Fluoride releasing restorative materials: Effects of $\mathrm{pH}$ on mechanical properties and ion release. Dent Mater. 2010;26(11):e227-35

30. Yoda A, Nikaido T, Ikeda M, Sonoda H, Foxton RM, Tagami J. Effect of curing method and storage condition on fluoride ion release from a fluoride-releasing resin cement. Dent Mater J. 2006;25(2):261-6.

31. Shimura R, Nikaido T, Yamauti M, Ikeda M, Tagami J. Influence of curing method and storage condition on microhardness of dual cure resin cements. Dent Mater J. 2005;24(1):70-5.

32. Momoi Y, McCabe JF. Fluoride release from light-activated glass ionomer restorative cements. Dent Mater 1993; 9:151-4.
33. Tay FR, Pashley DH, Suh BI, Carvalho RM, Itthagarum A. Single-step adhesives are permeable membranes. J Dent 2002; 30: 371-82.

34. Attar N, Turgut MD. Fluoride release and uptake capacities of fluoride-releasing restorative materials. Oper Dent 2003; 28:395-402.

35. Jingarwar MM, Pathak A, Bajwa NK, Sidhu HS. Quantitative assessment of fluoride release and recharge ability of different restorative materials in different media: An in-vitro study. J Clin Diagn Res. 2014; 8:31- 4.

36. Zafar MS. Effects of surface pre-reacted glass particles on fluoride release of dental restorative materials. World App Sci J. 2013; 28:457-62.

37. Freedman R, Diefenderfer KE. Effects of daily fluoride exposures on fluoride release by Glass ionomer based restoratives. Oper Dent 2003; 28:178-85

38. Takahashi K, Emilson CG, Birkhed D. Fluoride release in vitro from various glass ionomer cements and resin composites after exposure to NaF solutions. Dent Mater 1993;9 (6):350-4.

39. Wiegand A, Buchalla W, Attin T. Review on fluoride-releasing restorative materials Fluoride release and uptake characteristics, antibacterial activity and influence on caries formation. Dent Mater 2007; 23:343-62.

40. Preston AJ, Agalamanyi EA, Higham SM, Mair LH. The recharge of esthetic dental restorative materials with fluoride in vitro-two years' results. Dent Mater 2003; 19:32-7.

41. Lopes CM, Galvan J, Chibinski AC, Wambier DS. Fluoride release and surface roughness of a new glass ionomer cement: glass carbomer. Rev Odontol UNESP. 2018; 47(1): 1-6 